\title{
Modeling the lateral response of pile groups in cohesionless and cohesive soils
}

\author{
Jasim M. Abbas Al-Shamary*, Zamri Chik² and Mohd Raihan Taha²
}

${ }^{*}$ Correspondence: jasimalshamary@yahoo.com ${ }^{1}$ Department of Civil Engineering, Diyala University, Diyala, Baqubah 32001, Iraq Full list of author information is available at the end of the article

\begin{abstract}
A three-dimensional finite element approach was used to assess the lateral pile and pile group response subjected to pure lateral load. The study evaluated three pile group configurations (i.e. $2 \times 1,2 \times 2$ and $3 \times 2$ pile groups) with four values of pile spacing (i.e. $2 D, 4 D, 6 D$ and $8 D$, where $D$ is the pile diameter). The results of the influence of load intensities, group configuration, pile spacing are discussed in terms of response of load vs. lateral displacement, load vs. soil resistance and corresponding $p-y$ curves. The improved plots can be used for laterally loaded pile design and also to produce the group action design $\mathrm{p}$-multiplier curves and equations. As a result, design curves were developed and applied in the actual case studies and similar expected cases for assessment of pile group behavior using improved p-multiplier. A design equation was derived from predicted design curves to be used in the evaluation of the lateral pile group action. The equation was used with the previous results to predict the expected design curve take in the account different source of $p$-multiplier. It was found that the group interaction effect led to reduced lateral resistance for the pile in the group relative to that for the single pile. In addition, the present study was compatible with the results of previous results for the first and second trailing row and was less compatible with the result from the previous works in the case of piles in leading row.
\end{abstract}

Keywords: Piles, Pile group, Spacing, Configuration

\section{Introduction}

The lateral pile response of single isolated pile is important to understand and predict as reported by a number of researchers. However, pile within a group is equally important to investigate because generally the pile group consisting of a number of piles instills close proximity to one another [2, 24]. These close piles are usually fixed on the top and near to the ground surface by pile cap. The influence of a pile on the performance of an adjacent pile, termed pile-soil-pile interaction, can have significant effects $[1,7,22,28$, $29,31,32]$. However, in case of laterally performance closely spaced pile groups, the failure zones for both front and trailing rows piles are overlap with other leading row piles that usually decrease lateral resistance, as shown in Fig. 1.

Several methods have been developed over the years for assessing the lateral performance of pile within a closely spaced group. These methods are classified under five categories, as: (a) empirical stiffness distribution method [8], (b) hybrid model [9] (c) characteristic load method [21] (d) continuum methods [12], and (e) finite element method [15].

(c) The Author(s) 2018. This article is distributed under the terms of the Creative Commons Attribution 4.0 International License (http://creativecommons.org/licenses/by/4.0/), which permits unrestricted use, distribution, and reproduction in any medium, provided you give appropriate credit to the original author(s) and the source, provide a link to the Creative Commons license, and indicate if changes were made. 


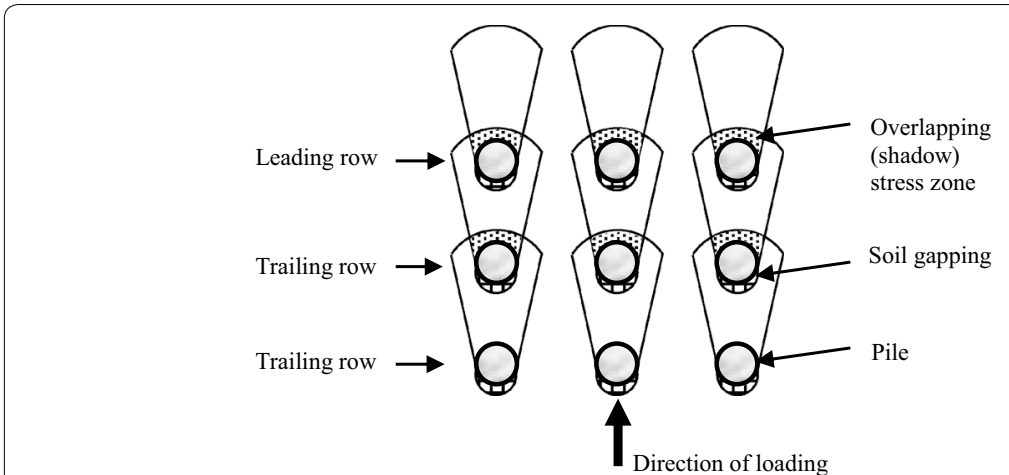

Fig. 1 Illustrated of reduction in lateral pile resistance due to pile-pile interface (Reproduced with permission from Rollins et al. [27] and Ashour et al. [1])

The purpose of this paper is to determine the relationship between pile spacing and p-multipliers $\left(f_{m}\right.$-pile-to-pile modulus multiplier $)$ for a laterally loaded pile-group in two types of soil (i.e. cohesionless and cohesive soils). In addition, the appropriate p-multipliers for a 3-pile group configuration at 2D, 4D, 6D and 8D pile spacing is also determined. Furthermore, this paper aims to access the accuracy of the p-multiplier concept for providing reasonable estimates of load pile displacement and lateral soil distribution in a pile group. Finally, improved both design curves and equation depends on the results from present study and existing data.

\section{Modeling and computational methods}

A plan view of an idealized prototype of pile group with vertical pile diameter, $\mathrm{D}$, length $\mathrm{L}$ and group dimensions $\left(\mathrm{L}_{\mathrm{Gr}} \times \mathrm{W}_{\mathrm{Gr}}\right)$ is shown in Fig. 2. The pile group configuration of a single row of pile $(2 \times 1)$, square $(2 \times 2)$ pile group and rectangular $(3 \times 2)$ pile group. It is assumed that the pile head is within the ground surface elevation. The surrounding soil is assumed to be homogenous saturated representing both cohesionless and cohesive soils. The pile cap is assumed to be rigid and therefore every pile carries an equal amount of the load. In addition, it is assumed that no pile cap resistance is present on the applied load (i.e. only distributing the loads to the pile head).

The analysis consists of modeling of single pile and pile cap using linear-elastic model with 15-node wedge elements. The cross-section of the pile is circular with a diameter of $1.0 \mathrm{~m}$ and length of $15 \mathrm{~m}$. The baseline soil parameters used for the analysis of laterally loaded pile group are illustrated in Table 1.

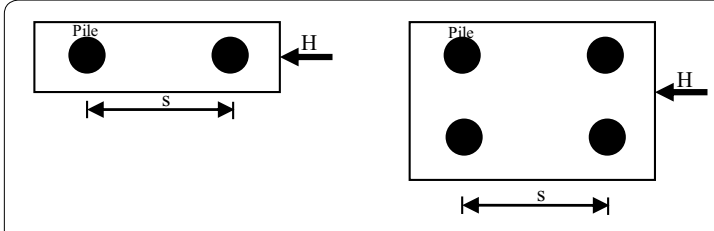

a

b

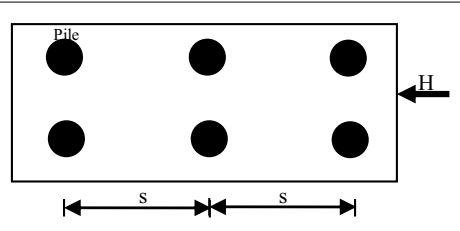

c

Fig. 2 Pile group configurations used in this study, a single row of pile $(2 \times 1)$, b square $(2 \times 2)$ pile group and $\mathbf{c}$ rectangular $(3 \times 2)$ pile group 
Finite element analyses were performed using the software PLAXIS 3D FOUNDATION [3]. In the finite element method a continuum is divided into a number of (volume) elements. Each element consists of a number of nodes. Each node has a number of degrees of freedom that correspond to discrete values of the unknowns in the boundary value problem to be solved.

Analyses were performed with several trial meshes with increasing mesh refinement until the displacement changes very minimal with more refinement. The aspect ratio of elements used in the mesh is small close to the pile body, near to the pile cap and piles bases. All the nodes of the lateral boundaries (right and bottom of Fig. 3) are restrained from moving in the normal direction to the respective surface. The predicted results from the three-dimensional finite element simulation are compared with that from analyses involving a single isolated pile in the same typical condition.

The outer boundaries of soil body of cubic shape are extended 10D on the sides and $5 \mathrm{D}$ to the bottom of pile group. The $3 \mathrm{D}$ view of the finite element mesh of the pile groups and the surrounding soil mass is shown in Fig. 1 . The outer dimensions of pile cap depend on the pile group arrangement. The pile cap extends about $0.5 \mathrm{~m}$ beyond the outside face of exterior piles. The finite element simulation includes the following constitutive relationships for pile, surrounding soil and interface element.

\section{Structural members model}

The use of the linear elastic model is quite common to model massive structures in the soil or bedrock layers which include piles, etc. [3]. This model represents Hooke's law of isotropic linear elasticity used for modeling the stress-strain relationship of the pile material. The model involves two elastic stiffness parameters, namely the effective Young's modulus, $\mathrm{E}^{\prime}$, and the effective Poisson's ratio, $v^{\prime}$.

\section{Soil model}

The surrounding soil is represented by the Mohr-Coulomb's model. This elasto-plastic model is based on soil parameters that are known in most practical situations. The model involves two main parameters, namely the cohesion intercept, $c^{\prime}$ and the friction angle, $\phi^{\prime}$. In addition, three parameters namely Young's modulus, $E^{\prime}$, Poisson's ratio, $v^{\prime}$, and the dilatancy angle, $\psi^{\prime}$ are needed to calculate the complete stress-strain $(\sigma, \varepsilon)$ behavior. The failure envelope as referred by Potts and Zdravkocic [23] and Johnson et al. [14] only depends on the principal stresses $\left(\sigma_{1}{ }^{\prime}, \sigma_{3}{ }^{\prime}\right)$, and is independent of the intermediate principle stress $\left(\sigma_{2}{ }^{\prime}\right)$.

Table 1 Soil parameters for analysis of pile group

\begin{tabular}{llll}
\hline Parameter & Unit & Cohesionless soil & Cohesive soil \\
\hline Unit weight, $y^{\prime}$ & $\mathrm{kN} / \mathrm{m}^{3}$ & 20.0 & 18.0 \\
Young's modulus, $E^{\prime}$ & $\mathrm{MPa}$ & $1.3 \times 10^{4}$ & $1.0 \times 10^{4}$ \\
Poisson's ratio, $v^{\prime}$ & - & 0.3 & 0.35 \\
Cohesion intercept, $c^{\prime}$ & - & 0.0 & 5.0 \\
Angle of internal friction, $\varnothing^{\prime}$ & - & 30 & 25 \\
\hline
\end{tabular}




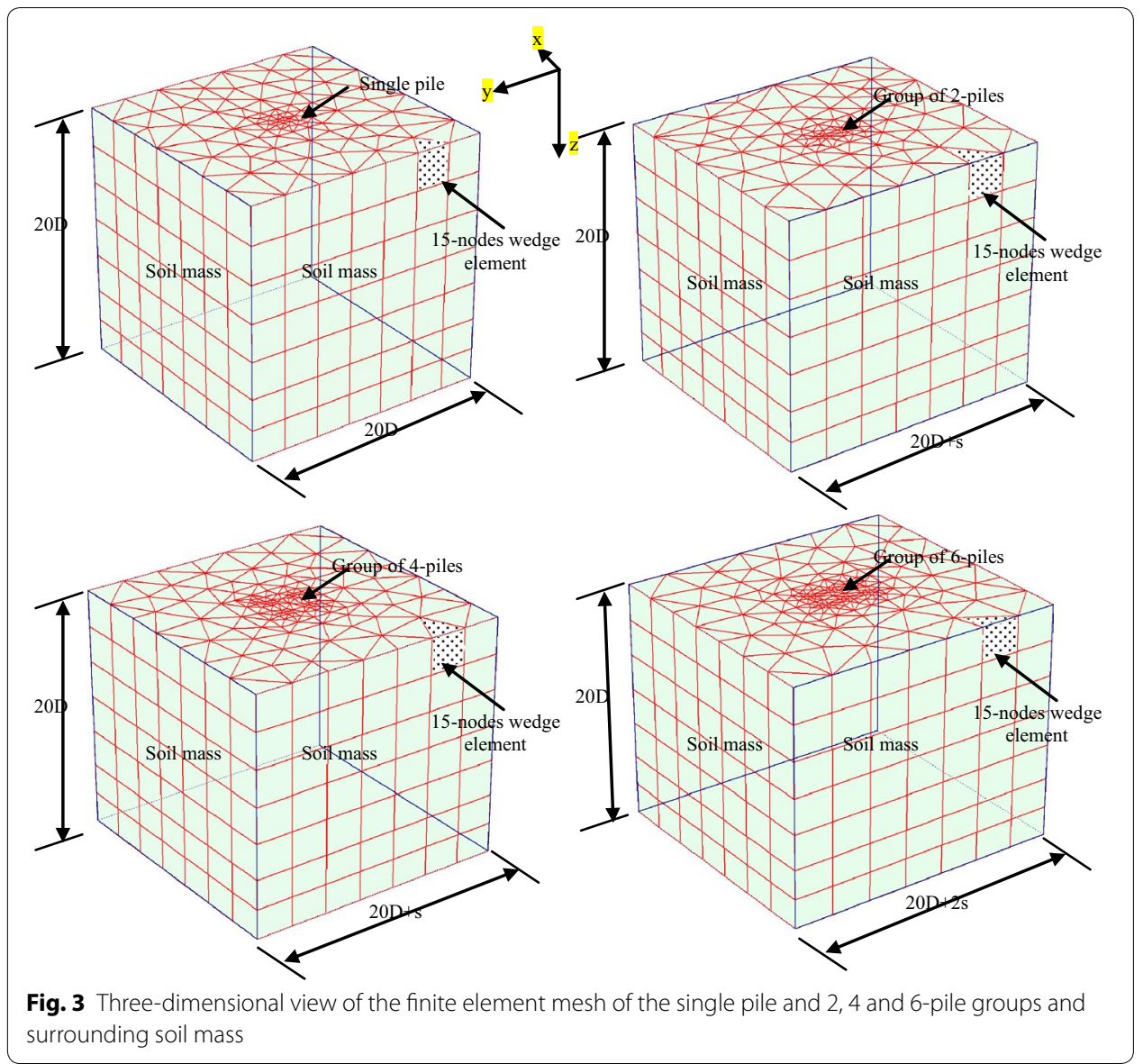

\section{Interface elements model}

In this study, interfaces are modelled as 16-node interface elements. Interface elements consist of eight pairs of nodes, compatible with the 8-noded quadrilateral side of a soil element. Along degenerated soil elements, interface elements are composed of six node pairs, compatible with the triangular side of the degenerated soil element. Each interface has a virtual thickness assigned to it which is an imaginary dimension used to obtain the stiffness properties of the interface. The virtual thickness is defined as the virtual thickness factor times the average element size. The average element size is determined by the global coarseness setting for the 2D mesh generation. The default value of the virtual thickness factor that is used in this study is 0.1 . The stiffness matrix for quadrilateral interface elements is obtained by means of Gaussian integration using $3 \times 3$ integration points. The position of these integration points (or stress points) is chosen such that the numerical integration is exactly for linear stress distributions. The 8-node quadrilateral elements provide a second-order interpolation of displacements. Quadrilateral elements have two local coordinates ( $\xi$ and $\eta)$.

\section{Validation of the numerical model}

This section assesses the accuracy of the finite element approach in analyzing laterally loaded pile foundation and to verify certain details of the finite element such as pile displacement. According to the literature, there are no published cases of full-scale lateral 
pile response subjected to a different combination of axial and lateral loads. Therefore, this case deals with a full-scale axial loaded pile [13] to make a comparison with a case study of axial loaded piles. Results of laboratory and field tests are used to identify the soil profiles and soil properties, pile load tests are well instrumented. The case study consists of a large diameter bored piles of $1.2 \mathrm{~m}$ diameter which were used for the construction of a new $2.2 \mathrm{~km}$ road dual carriageway viaduct on an existing road [13]. The road project is situated in Port Klang, and links the West Port to Kuala Lumpur, Malaysia. The piles were tested vertically to assess the axial bearing capacity of designed piles. The length of each bored pile is approximately $75 \mathrm{~m}$ with steel casing being used for the top $30 \mathrm{~m}$. The bored piles were designed to carry loads ranging from 300 to $600 \mathrm{kN}$. The generalized subsoil properties consist of very soft silty clay with traces of sea shells with depth $20 \mathrm{~m}$. Below this layer is a $10 \mathrm{~m}$ of soft silty clay followed by a layer of medium dense to dense silty sand and medium stiff silty clay of about 20 and $7 \mathrm{~m}$ depth, respectively. Finally the lowest layer consists of very dense fine grained sand. Comparable data were obtained between the experimental results of the three piles and the presented simulation model in the case of axial test. The magnitude of deflection of the piles was not the same as the field test due possibly to the variability of soil properties. The result obtained from the finite element simulation is closer to the result measured from pile number one.

\section{Assessment of lateral pile displacement}

The influence of group interaction on the three pile groups (i.e. $2 \times 1,2 \times 2$ and $3 \times 2$ ) on the lateral pile displacement at four different pile spacing (i.e. $s=2 \mathrm{D}, 4 \mathrm{D}, 6 \mathrm{D}$ and $8 \mathrm{D}$ ) is shown in Figs. 4 and 5. In general, it can be observed that the lateral pile displacement of pile group (all pile spacing) are less than the results obtained from the assessment on single isolated pile as shown in Fig. 4. For the same magnitude of lateral load of $450 \mathrm{kN}$, group interaction obtained showed an increase in lateral pile displacement. This conclusion was also supported by Brown et al. [5], and Rollins et al. [20-29]. It can be seen that the pile spacing less than $6 \mathrm{D}$ resulted in a large lateral deflection of a pile group under applied load due to group high group interaction effect. This is also supported by Zhang and Small [31]. From these results, and in case of $\mathrm{s}=80$, the observed lateral pile displacement and lateral soil pressure values are usually close to the values obtained from the single isolated pile analysis.

The behavior of the pile group $2 \times 2$ is comparable but not the same as the behavior of the previous group analyzed (i.e. $2 \times 1$ ). Parta and Pisa [22] obtained the same results. This is due to the same number of piles in the direction parallel with the load direction. Therefore, similar discussion can be obtained for the general behavior of this type of pile group. Moreover, the group interaction increased the lateral pile displacement and reduces on the lateral soil resistance as shown in Fig. 4.

The main difference between $3 \times 2$ pile group with the other two previous types (i.e. $2 \times 1$ and $2 \times 2$ ) is the increase in the number of rows. This type has additional intermediate row i.e. second row or intermediate row or middle row and/or 2nd trailing row $[1,22,25,28,29,32]$. It can be observed that the values in both first and second trailing row of the lateral pile displacement and lateral soil resistance are very close which were similarly observed by Zhang et al. [32] and Rollins et al. [28, 29]. It can 


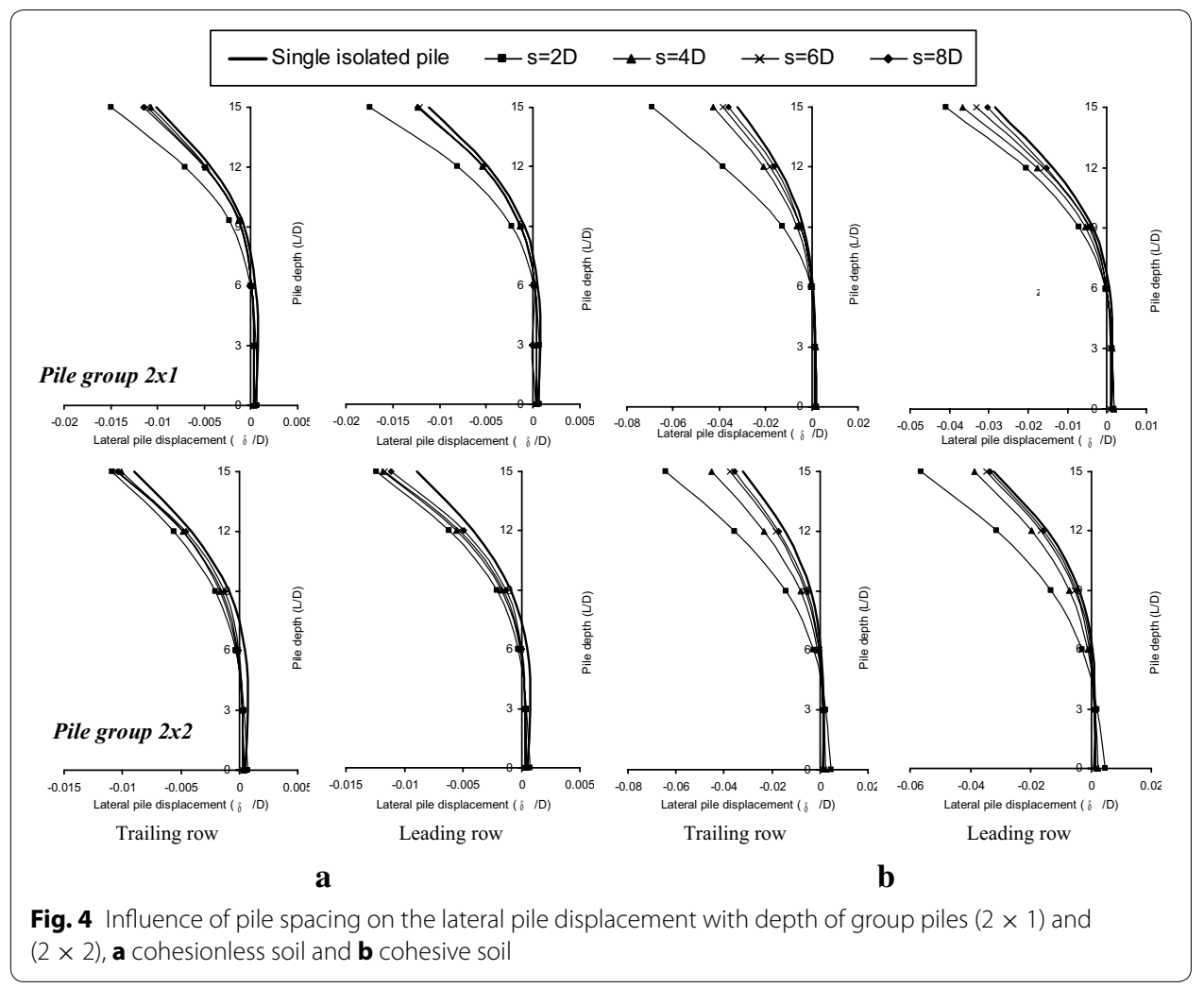

be seen that the values of first trailing row are significantly greater than the values observed from the second trailing row which was also obtained by Brown et al. [5]. This is possibly due to the group interaction with more effect on the intermediate rows as shown in Fig. 5.

\section{Assessment of lateral soil pressure}

The influence of group interaction on the three pile groups (i.e. $2 \times 1,2 \times 2$ and $3 \times 2$ ) on the lateral soil pressure at four different pile spacing (i.e. $s=2 \mathrm{D}, 4 \mathrm{D}, 6 \mathrm{D}$ and $8 \mathrm{D}$ ) are shown in Figs. 6 and 7. The ultimate soil resistance versus depth for both cohesionless and cohesive soil with four different pile spacing is shown in Fig. 6. The difference in ultimate soil resistance for the same amount of lateral load (i.e. $450 \mathrm{kN}$ ) due to the effect of pile spacing is significant. The ultimate soil resistance of laterally loaded piles decreases significantly with increase in pile spacing [5, 20-29]. It can also be observed that, in the case of $2 \times 2$ pile group the pile in same row has same lateral capacity. However, in case of $3 \times 2$ group, the piles in the second trailing row carry different capacities compared with both first and Leading row as illustrated in Fig. 7. These values is almost close with that obtained from the first trailing row which were also observed by Zhang et al. [32], and Rollins et al. [28, 29]. 


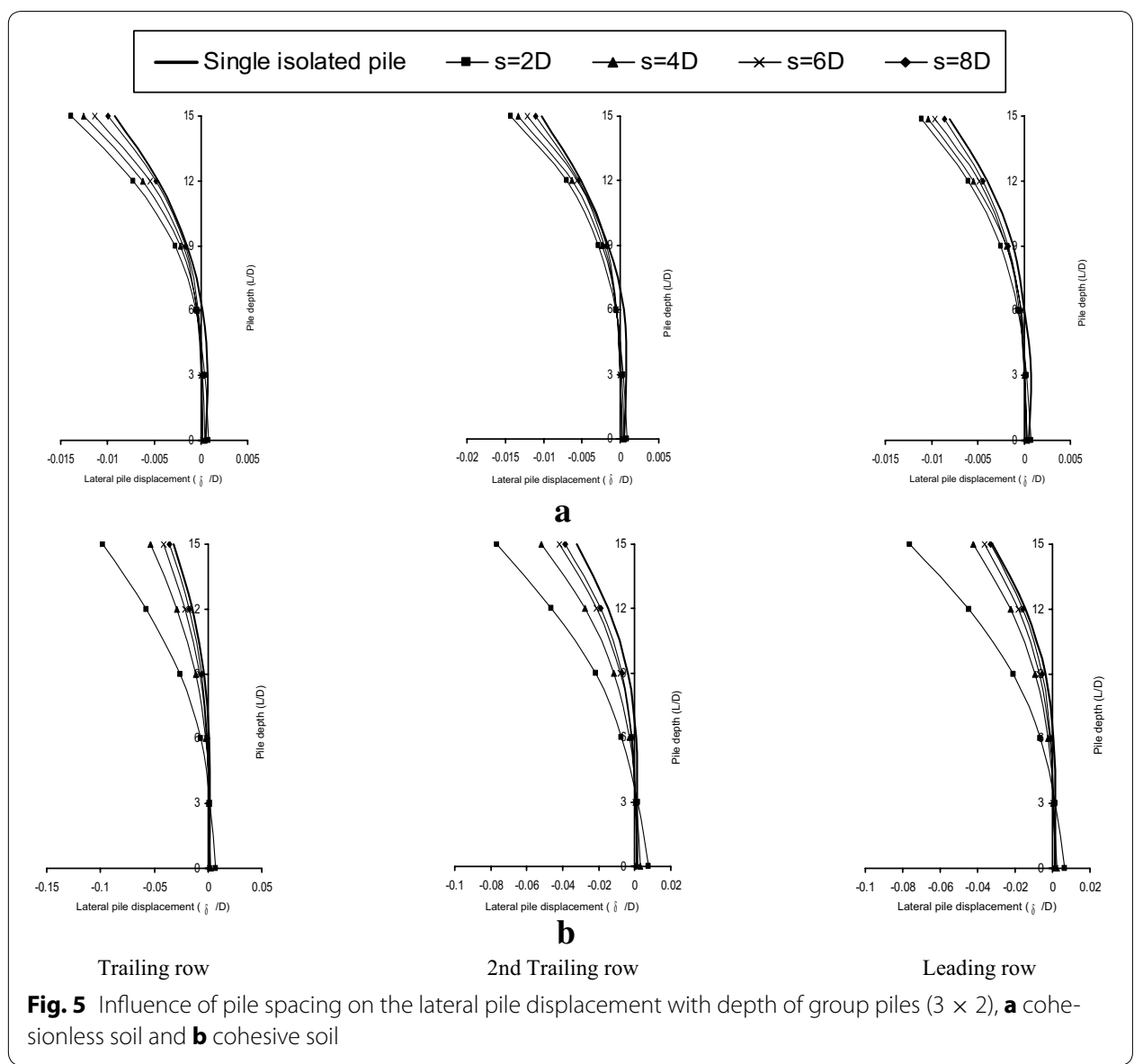

\section{Development of $p-y$ design curves}

The influence of group interaction on the three pile groups (i.e. $2 \times 1,2 \times 2$ and $3 \times 2$ ) on predicted $\mathrm{p}-\mathrm{y}$ design curves at four different pile spacing (i.e. $\mathrm{s}=2 \mathrm{D}, 4 \mathrm{D}, 6 \mathrm{D}$ and $8 \mathrm{D}$ ) are shown in Fig. 8. The predicted p-y curve was evaluated at a depth of $3 \mathrm{~m}$, because this is the depth with maximum ultimate lateral soil pressure. It can be observed that there are significant difference on the $\mathrm{p}-\mathrm{y}$ curve of close pile group (i.e. $\mathrm{s}=2 \mathrm{D}$ ). This is due to increase of lateral pile displacement and loss on the lateral soil pressure. The pile within leading row has significantly close values with that obtained from single isolated pile. This is due to the reduction on the group action on the leading row unlike the piles within other rows (i.e. trailing row). This is also reported by Brown et al. [5] and Rollins et al. [20-29]. Same discussion obtained from predicted $p-y$ curve of group $2 \times 1$ can be applied for both pile group $2 \times 2$ and $3 \times 2$.

\section{Prediction of the pile-to-pile modulus multiplier and proposed equation for analyses of pile groups}

As reported by Rollins et al. [28, 29], one method of accounting for the shadowing or group action effects is to reduce the modulus or the soil resistance, $p$ for the pure laterally loaded pile group. This module is named p-multiplier $\left(f_{m}\right)$ which is usually derived from a single isolated pile and pile within group $\mathrm{p}-\mathrm{y}$ curve which was earlier proposed 


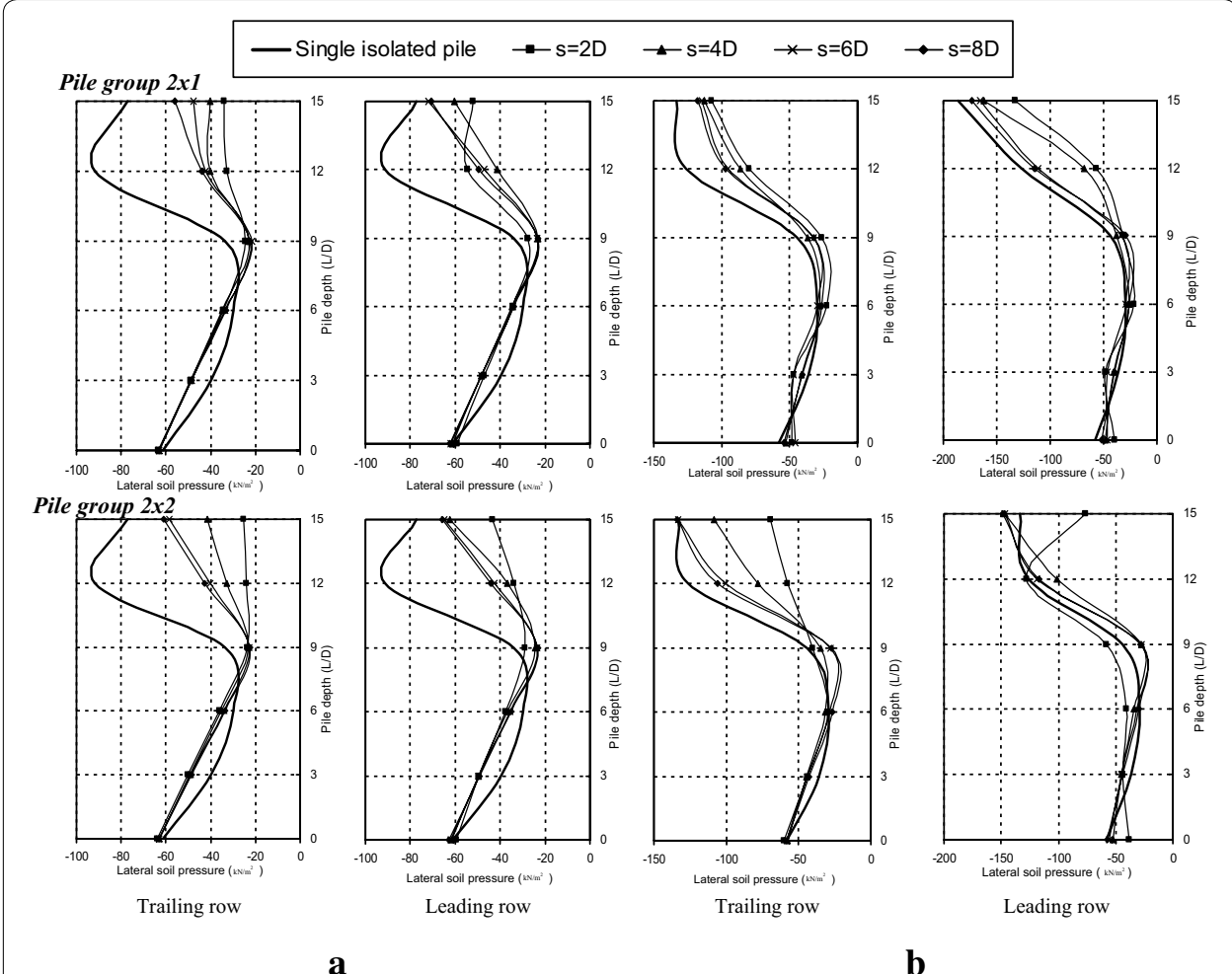

Fig. 6 Influence of pile spacing on the lateral soil pressure with depth of group piles $(2 \times 1)$ and $(2 \times 2)$, a cohesionless soil and $\mathbf{b}$ cohesive soil

by Brown et al. [5]. Although this simple approach has provided relatively good estimates of measured pile group behavior [5,27], p-multipliers are extremely restricted in their application. These previous researches obtained the pile-to-pile modulus multiplier only for specific soil type and method of prediction. No reports are available for the influence of soil type and method of prediction on the p-multiplier. Therefore, this section provides the development of the $f_{m}$ with respect to pile spacing for pure lateral loaded pile groups in cohesionless and cohesive soils. The improvement includes:

1. Proposed design curve show p-multiplier values as a function of pile spacing.

2. Proposed design equation to compute the amount of p-multiplier $\left(f_{m}\right)$ as a function of both pile spacing $(\mathrm{c}-\mathrm{c})$ and pile diameter (D).

\section{Proposed design curve}

In general, the fundamental procedure for obtained pile-to-pile modulus multiplier $\left(f_{m}\right.$ or p-multipliers) was evaluated by dividing the ultimate soil pressure of the pile within group by the values obtained from the single isolated pile at the specific depth $[5,28,30]$. Predicted p-y curve for pile within group can be obtained by multiplying the values of lateral soil pressure $\mathrm{p}$ by the value of $\left(f_{m}\right)$ while keeping lateral pile displacement constant. The results of the predicted p-multipliers represents both cases of purely lateral loaded pile groups is illustrated in Fig. 9. 


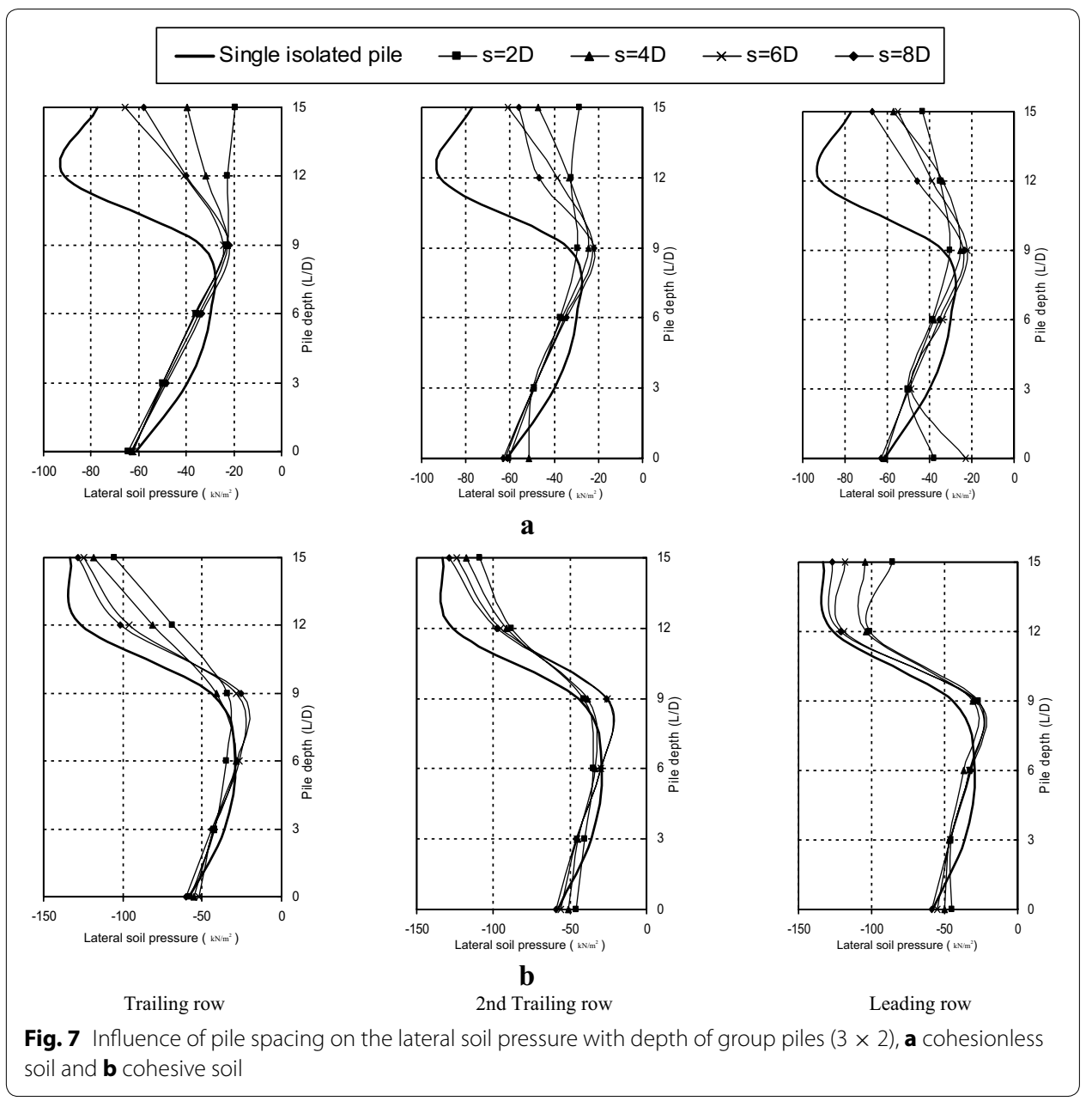

It can be observed that the values of the $f_{m}$ of leading pile is always greater that those measured for first and second trailing pile which was also observed previously by Brown et al. [5], Ruesta and Townsend [30], Rollins et al. [28]. Therefore the piles in the leading row carry load magnitude similar to that carried by single isolated pile. This is due to the less effect of group action on the leading pile compared with other piles.

The piles in first and second trailing row also carry similar magnitudes of loads. It seems that pile spacing between $(\mathrm{s}=2 \mathrm{D}-5 \mathrm{D})$ also give small values of $f_{m}$. This means large effect of group action occurred in the case of small pile spacing compared with the pile group of wide pile spacing (i.e. $s$ is more than $5 \mathrm{D}$ ). This indicate that the pile within the group for the case of wide spacing pile group can be designed according to the results obtained from single isolated pile.

\section{Proposed design equation}

A design equation has also been developed according to the design p-multiplier curves to compute the amount of $\mathrm{p}$-multiplier $\left(f_{m}\right)$ as a function of both pile spacing $(\mathrm{c}-\mathrm{c})$ and pile diameter (D). The equation applied for both cohesionless and cohesive soils is:

$$
f_{m}=A \operatorname{Ln}(s / D)+B \geq 1.0
$$




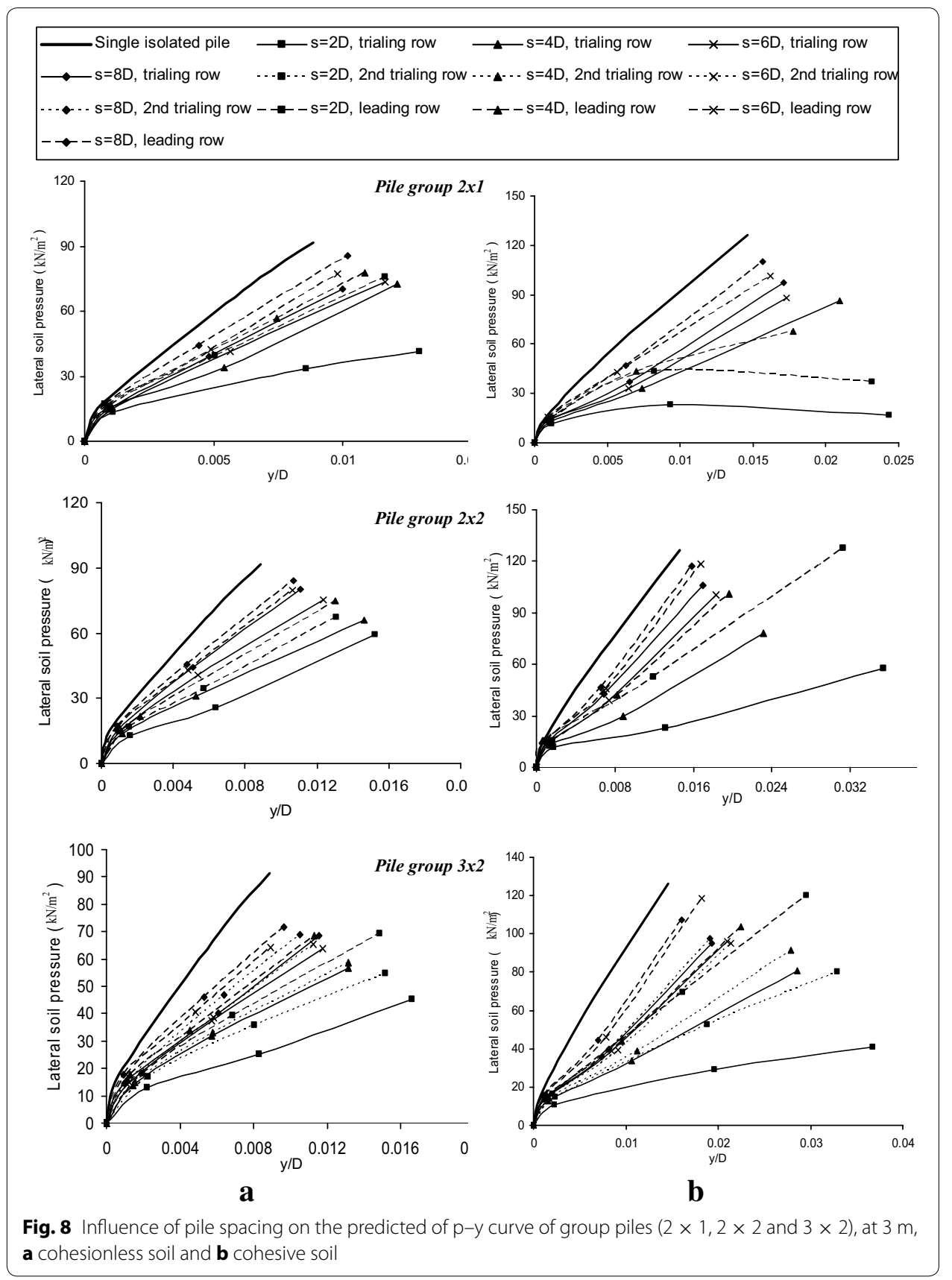

where $\mathrm{A}$ and $\mathrm{B}$ are constant which can directly obtained from Table 2.

Table 2 is limited for three pile group configuration (i.e. $2 \times 1,2 \times 2$ and $3 \times 2$ ) and four pile spacing (i.e. $s=2 \mathrm{D}, 4 \mathrm{D}, 6 \mathrm{D}$ and $8 \mathrm{D}$ ). The values of these constants can extrapolate to other pile group configurations.

The predicted p-multipliers from this studies is generally in good agreement with those obtained from previous studies in both cohesionless and cohesive soils for the case of pure lateral load which are tabulated in Table 3. The comparison made with respect to the pile group configuration were represented by three configurations (i.e. $2 \times 1$ line pile group, $2 \times 2$ square pile group and $3 \times 2$ rectangular pile group). The values of 


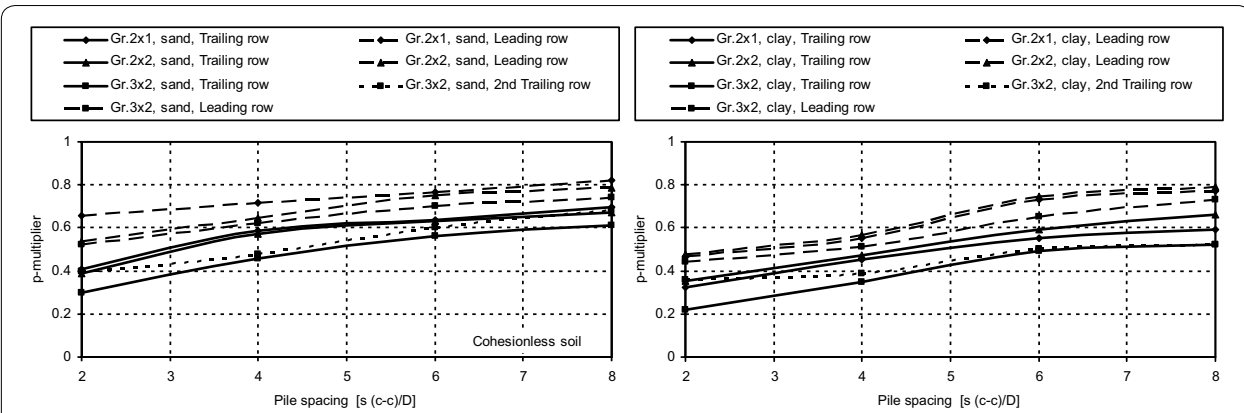

Fig. 9 Predicted $p$-multiplier for purely lateral loaded pile group embedded in both cohesionless and cohesive soil, at $3 \mathrm{~m}$ depth, (groups $2 \times 1,2 \times 2$ and $3 \times 2$ )

Table 2 Values of A and B constants for both cohesionless and cohesive soil

\begin{tabular}{|c|c|c|c|c|c|c|}
\hline \multirow[t]{2}{*}{ Group configuration } & \multicolumn{2}{|c|}{ Trailing row } & \multicolumn{2}{|c|}{ 2nd Trailing row } & \multicolumn{2}{|c|}{ Leading row } \\
\hline & $A$ & B & $A$ & B & A & B \\
\hline & \multicolumn{6}{|c|}{ Cohesionless soil } \\
\hline $2 \times 1$ & 0.2031 & 0.2806 & - & - & 0.1154 & 0.5686 \\
\hline $2 \times 2$ & 0.2075 & 0.2575 & - & - & 0.1867 & 0.4018 \\
\hline \multirow[t]{2}{*}{$3 \times 2$} & 0.2272 & 0.1445 & 0.2014 & 0.2403 & 0.1612 & 0.4052 \\
\hline & \multicolumn{6}{|c|}{ Cohesive soil } \\
\hline $2 \times 1$ & 0.2234 & 0.187 & - & - & 0.2356 & 0.2955 \\
\hline $2 \times 2$ & 0.1973 & 0.1852 & - & - & 0.2292 & 0.289 \\
\hline $3 \times 2$ & 0.2304 & 0.0543 & 0.1246 & 0.2578 & 0.2092 & 0.2718 \\
\hline
\end{tabular}

$\left(f_{m}\right)$ which resulted from previous works and proposed equation are compared and predict average curve. The new curves are obtained from different measurements of various experimental and analytical tests. These curves represent the possible response of the pile groups when carrying pure lateral load. The magnitudes of $f_{m}$ obtained from this comparison taken as average values for all $f_{m}$ from both previous and this study.

The average curves presented in Fig. 10 were computed using data from both previous works (i.e. published cases) and presents a finite element assessment. It can be observed that the finite element modeling is gave same time closed results with those observed from the exist cases, other time gave not related results compared with those predicted from previous studies. This is possibly due to the different methods for assessing the lateral pile group response (e.g. full-scale test, small physical model test, centrifugal test and theoretical analysis). Both results (i.e. previous works and present finite element assessment) compares well when evaluating the piles in trailing and 2nd trailing rows with little similarities when assessing the pile in leading row. The present assessment is more conservative (i.e. safer) with the piles in trailing rows and always give factor of safety more to the piles in the leading row. Therefore the present finite element assessment is compatible with the outcome from previous results (i.e. similar design curve) for first and second trailing row and was less compatible with the result from the previous works (i.e. give more safety) in the case of piles in leading row. Based on the average curve, it can be derived an equation represent average values, the equation is: 
Table 3 Comparison of $f_{m}$ obtained from the present study with publishing cases

\begin{tabular}{|c|c|c|c|c|c|c|c|c|c|}
\hline \multirow[t]{3}{*}{ Reference } & \multirow{3}{*}{$\begin{array}{l}\text { Group } \\
\text { Config. }\end{array}$} & \multirow{3}{*}{$\begin{array}{l}\text { Pile } \\
\text { spacing }\end{array}$} & \multirow{3}{*}{$\begin{array}{l}\text { Soil } \\
\text { type }\end{array}$} & \multicolumn{6}{|c|}{ p-Multipliers by row } \\
\hline & & & & \multicolumn{2}{|c|}{ Trailing row } & \multicolumn{2}{|c|}{ 2nd trailing row } & \multicolumn{2}{|c|}{ Leading row } \\
\hline & & & & $\begin{array}{l}\text { Refer- } \\
\text { ence }\end{array}$ & $\begin{array}{l}\text { This } \\
\text { study }\end{array}$ & $\begin{array}{l}\text { Refer- } \\
\text { ence }\end{array}$ & $\begin{array}{l}\text { This } \\
\text { study }\end{array}$ & $\begin{array}{l}\text { Refer- } \\
\text { ence }\end{array}$ & $\begin{array}{l}\text { This } \\
\text { study }\end{array}$ \\
\hline \multirow[t]{3}{*}{ Lieng [18] } & \multirow[t]{3}{*}{$2 \times 1$} & $2 \mathrm{D}$ & \multirow[t]{3}{*}{ Sand } & 0.33 & 0.42 & - & - & \multirow{3}{*}{$\begin{array}{l}\text { Not } \\
\text { meas- } \\
\text { ured }\end{array}$} & 0.65 \\
\hline & & $4 \mathrm{D}$ & & 0.8 & 0.56 & - & - & & 0.73 \\
\hline & & $6 \mathrm{D}$ & & 1.0 & 0.65 & - & - & & 0.78 \\
\hline \multirow{3}{*}{$\begin{array}{l}\text { Brown and } \\
\text { Shie [6] }\end{array}$} & \multirow[t]{3}{*}{$2 \times 1$} & $2 \mathrm{D}$ & \multirow[t]{3}{*}{ Clay } & - & 0.34 & - & - & 0.8 & 0.46 \\
\hline & & $3 \mathrm{D}$ & & 0.5 & 0.43 & - & - & 0.9 & 0.55 \\
\hline & & $5 \mathrm{D}$ & & 0.8 & 0.55 & - & - & 1.0 & 0.68 \\
\hline \multirow{2}{*}{$\begin{array}{l}\text { Kotthaus } \\
\text { et al. [17] }\end{array}$} & \multirow[t]{2}{*}{$3 \times 1$} & $3 \mathrm{D}$ & \multirow[t]{2}{*}{ Sand } & 0.45 & 0.5 & - & - & 0.75 & 0.7 \\
\hline & & $4 \mathrm{D}$ & & 0.65 & 0.56 & - & - & 0.95 & 0.73 \\
\hline \multirow{3}{*}{$\begin{array}{l}\text { Remaud et al. } \\
\text { [26] }\end{array}$} & \multirow{3}{*}{$2 \times 1$} & $2 \mathrm{D}$ & \multirow[t]{3}{*}{ Sand } & 0.52 & 0.42 & - & - & 1.0 & 0.65 \\
\hline & & $4 \mathrm{D}$ & & 0.82 & 0.56 & - & - & 1.0 & 0.73 \\
\hline & & $6 \mathrm{D}$ & & 0.93 & 0.71 & - & - & 1.0 & 0.78 \\
\hline Ilyas [11] & $2 \times 1$ & $3 D$ & Clay & 0.63 & 0.43 & - & - & 0.8 & 0.55 \\
\hline $\begin{array}{l}\text { Chan- } \\
\text { drasekaran } \\
\text { et al. [7] }\end{array}$ & $2 \times 1$ & $3 D$ & Clay & 0.7 & 0.42 & - & - & 0.81 & 0.55 \\
\hline $\begin{array}{l}\text { Meimon et al. } \\
{[20]}\end{array}$ & $2 \times 2$ & $3 D$ & Clay & 0.5 & 0.4 & - & - & 0.9 & 0.54 \\
\hline $\begin{array}{l}\text { Brown et al. } \\
\text { [4] }\end{array}$ & $3 \times 3$ & $3 \mathrm{D}$ & Clay & 0.4 & 0.4 & - & - & 0.7 & 0.54 \\
\hline $\begin{array}{l}\text { Brown et al. } \\
\text { [5] }\end{array}$ & $3 \times 3$ & $3 \mathrm{D}$ & Sand & 0.3 & 0.49 & - & - & 0.8 & 0.61 \\
\hline $\begin{array}{l}\text { Rollins et al. } \\
\text { [27] }\end{array}$ & $3 \times 3$ & $2.82 \mathrm{D}$ & Clay & 0.4 & 0.39 & - & - & 0.6 & 0.53 \\
\hline Ilyas [11] & $2 \times 2$ & $3 D$ & Clay & 0.78 & 0.4 & - & - & 0.96 & 0.54 \\
\hline $\begin{array}{l}\text { Rollins et al. } \\
\text { [29] }\end{array}$ & $3 \times 3$ & $5.65 \mathrm{D}$ & $\begin{array}{l}\text { Clay and } \\
\text { sand }\end{array}$ & 0.77 & $\begin{array}{c}0.53 \\
0.62\end{array}$ & - & - & 0.95 & $0.69,0.72$ \\
\hline \multirow{2}{*}{$\begin{array}{l}\text { Chan- } \\
\text { drasekaran } \\
\text { et al. [7] }\end{array}$} & \multirow[t]{2}{*}{$2 \times 2$} & $3 D$ & Clay & 0.48 & 0.4 & - & - & 0.74 & 0.54 \\
\hline & & $5 \mathrm{D}$ & Clay & 0.58 & 0.5 & - & - & 0.85 & 0.66 \\
\hline $\begin{array}{l}\text { McVay et al. } \\
\text { [19] }\end{array}$ & $4 \times 3$ & $3 D$ & Sand & 0.3 & 0.39 & 0.4 & 0.46 & 0.8 & 0.58 \\
\hline $\begin{array}{l}\text { Huang et al. } \\
\text { [10] }\end{array}$ & $4 \times 3$ & $3 \mathrm{D}$ & Sand & 0.66 & 0.39 & 0.6 & 0.46 & 0.89 & 0.58 \\
\hline $\begin{array}{l}\text { Rollins et al. } \\
\text { [29] }\end{array}$ & $4 \times 3$ & $4.4 \mathrm{D}$ & $\begin{array}{l}\text { Clay and } \\
\text { sand }\end{array}$ & 0.73 & $0.4,0.48$ & 0.8 & $\begin{array}{c}0.44 \\
0.54\end{array}$ & 0.9 & $0.58,0.64$ \\
\hline
\end{tabular}

$$
f_{m}(\text { average })=A^{\prime}(s / D)+B^{\prime} \geq 1.0
$$

$A_{\text {(average) }}$ and $B_{(\text {average }}$ are constant can directly obtained from Table 4.

\section{Example calculation of the pile group}

The total lateral load resistance of a $2 \times 2$ pile group configuration is to be determining according to the assumed single pile response reported by Karthigeyan et al. [16] for both cohesionless and cohesive soils. This group has spacing of 3.53D center to center in the direction of lateral load. This value of pile spacing was also used by Rollins et al. [29]. For this example, the piles are 1.2 and $10.0 \mathrm{~m}$ diameter and length, respectively. The 


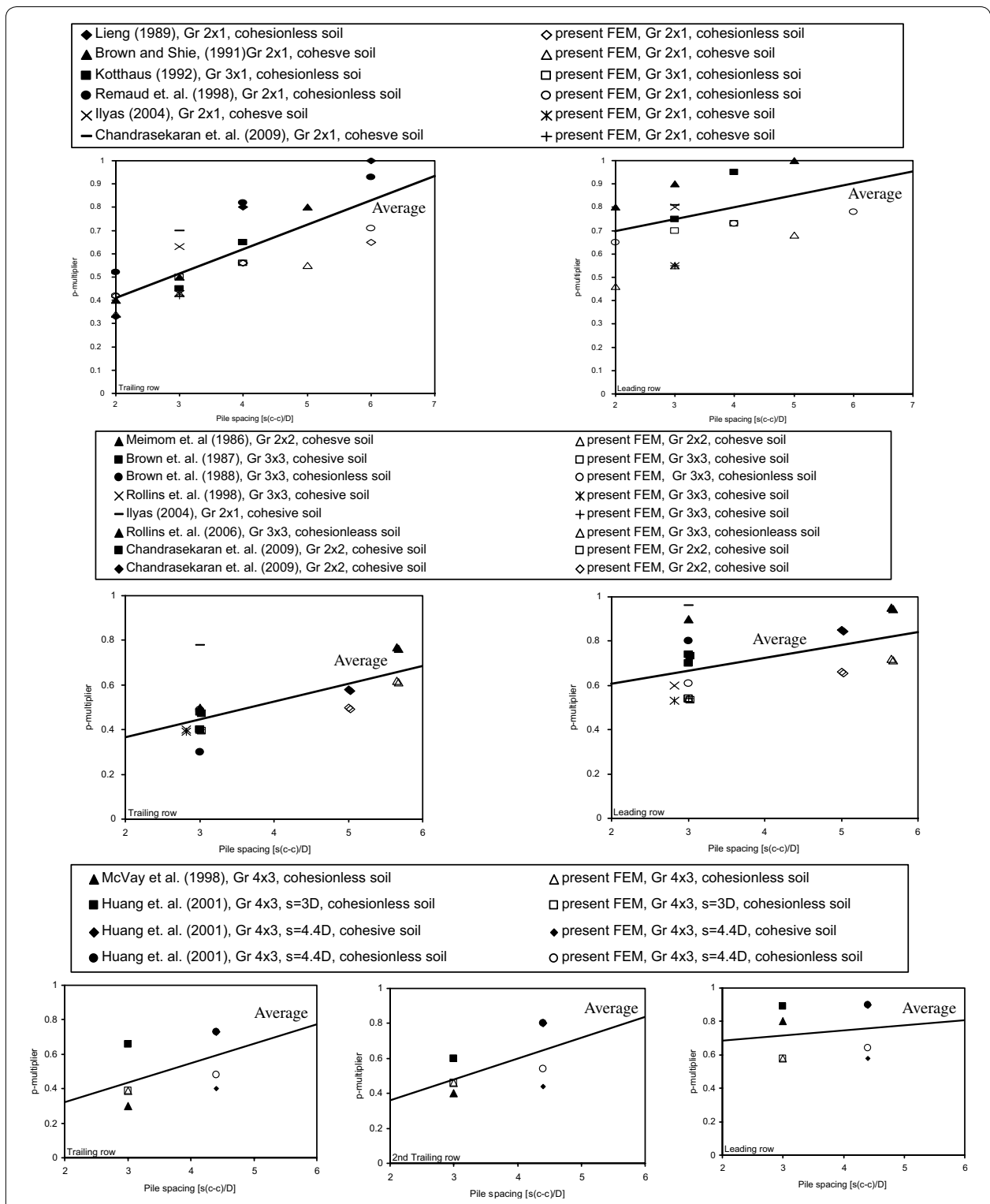

Fig. 10 Possible p-multiplier design curves as a function of pile spacing according to both previous works and present FEM

Table 4 Values of $C$ and $D$ constants for both cohesionless and cohesive soil

\begin{tabular}{|c|c|c|c|c|c|c|}
\hline \multirow[t]{2}{*}{ Group configuration } & \multicolumn{2}{|c|}{ Trailing row } & \multicolumn{2}{|c|}{ 2nd Trailing row } & \multicolumn{2}{|c|}{ Leading row } \\
\hline & $A^{\prime}$ & $\mathrm{B}^{\prime}$ & $A^{\prime}$ & $\mathbf{B}^{\prime}$ & $A^{\prime}$ & $\mathbf{B}^{\prime}$ \\
\hline $2 \times 1$ & 0.1042 & 0.2032 & - & - & 0.0519 & 0.5879 \\
\hline $2 \times 2$ & 0.0779 & 0.2107 & - & - & 0.0581 & 0.492 \\
\hline $3 \times 2$ & 0.1071 & 0.1136 & 0.1179 & 0.1264 & 0.0304 & 0.6214 \\
\hline
\end{tabular}

predicted $f_{m}$ magnitudes for this specific example are calculated using Eqs. 1 and 2 and the results are shown below.

Calculation based on Eq. 1: 

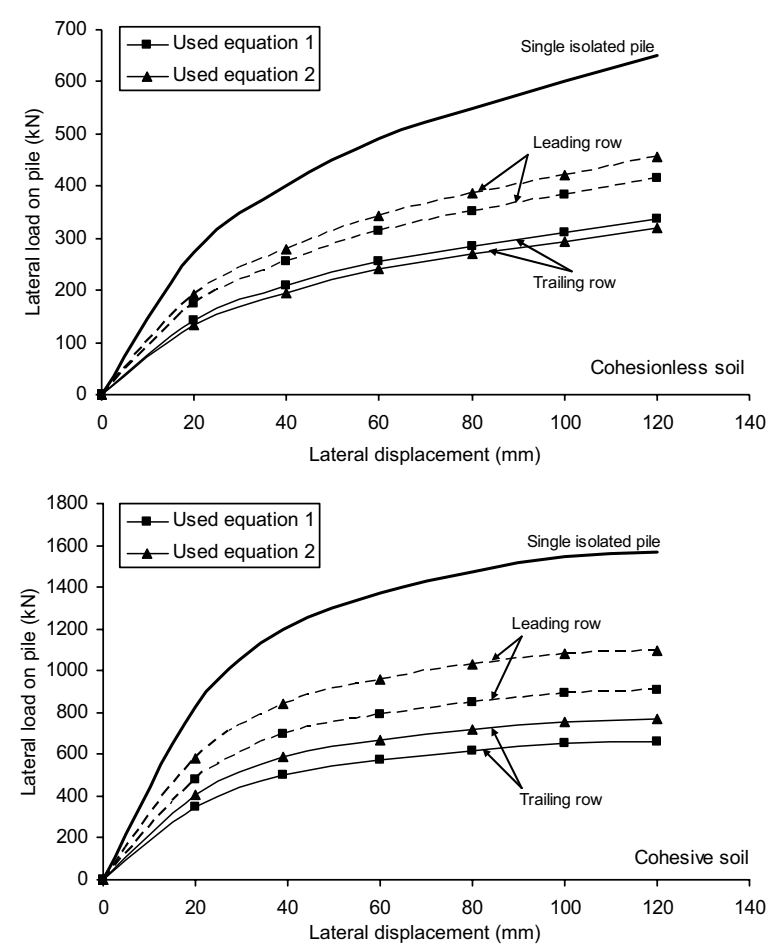

Fig. 11 Load-deflection curves obtained from the example of pile group with predicted computed from improved p-multiplier equations

Cohesionless soil:

Trailing rowspacing, $f_{m}=0.2075 \operatorname{Ln}(3.53)+0.2575=0.52$

Leading rowspacing, $f_{m}=0.1867 \operatorname{Ln}(3.53)+0.4018=0.64$

Cohesive soil:

Trailing rowspacing, $f_{m}=0.1973 \operatorname{Ln}(3.53)+0.1852=0.42$

Leading rowspacing, $f_{m}=0.2292 \operatorname{Ln}(3.53)+0.2890=0.58$

Calculation based on Eq. 2:

Trailing rowspacing, $f_{m}=0.0779(3.53)+0.2107=0.49$

Leading rowspacing, $f_{m}=0.0581(3.53)+0.4920=0.70$

The computed load vs. deflection for single isolated pile with $f_{m}$ values in case of cohesionless and cohesive soil are shown in Fig. 11. It can be observed that the results of two equations are very closed in case of trailing row and more significantly for the leading row. In addition, the results obtained from the two equations are greater in case of cohesionless soil compared with the case of cohesive soil. 


\section{Summary and evaluation of the results}

It is obvious, from the related literature of pile groups; there are little comparison available for the lateral pile group response in types of soil (i.e. cohesionless and cohesive soil). Thus, this study is includes two types of soil and different group configurations. This research has made it possible to quantify many important aspects of pile and pile group behavior subjected to pure lateral load.

To satisfy the objective of this study, a three-dimensional finite element approach is used to analyse this problem. The geotechnical system included linear elastic, MohrCoulomb and 16-node interface elements constitutive models. Three pile groups (i.e. $2 \times 1,2 \times 2$ and $3 \times 2$ ) with four varying pile spacings (i.e. 2D, 4D, 6D and 8D). Cohesionless and cohesive soils were used in this study. Lateral applied loads are 50, 250 and $450 \mathrm{kN}$.

The analysis of the pile group conducted in this study includes lateral pile displacement and lateral soil resistance with pile depth as well as the corresponding $\mathrm{p}-\mathrm{y}$ curves. The evaluation of these factors was assessed on the first and second trailing rows as well as the leading row. The resultant $\mathrm{p}-\mathrm{y}$ design curves can be used to produce the design parameters for laterally loaded pile design. In addition these curves can be used to create p-multiplier design curves. These curves can be used to predict the lateral behavior of pile within group when only the results of single isolated piles are available. The predicted p-multiplier design curves is used to developed design equation to compute the amount of p-multiplier $\left(f_{m}\right)$ as a function of both pile spacing (c-c) and pile diameter (D) under pure lateral loads.

In order to make comparison between present and predicted cases, the design equation was applied on the expected example assumed based on available repots that has 13 cases studies. This comparison shows that the results obtained from the equation is very closed with those obtained from the first and second trailing row, while, same time was not been fit with the results which was obtained for the case of leading row. The results obtained from both present and previous studies are used to generate a average curves for three pile group shapes (i.e. line, square and rectangular pile group shapes). The design equations were tested on an example based on Rollins et al. [29] and Karthigeyan et al. [16]. The calculation example gives the step by step application of these equations.

\section{Conclusions}

In general, the lateral pile displacement of pile group (all pile spacing) is less than the results obtained from assessment of single isolated pile. For the same magnitude of lateral load of $450 \mathrm{kN}$, group interaction made increase in lateral pile displacement and redistributed the lateral soil pressure. Pile spacing of less than 6D produced a large lateral deflection of a pile group under applied load. The values of the lateral pile displacement and lateral soil pressure observed are close to those obtained from the analysis of single isolated pile when the pile spacing is high (i.e. $\mathrm{s}=8 \mathrm{D}$ ).

Significantly large difference on the $\mathrm{p}-\mathrm{y}$ curve of closed spacing pile group (i.e. $\mathrm{s}=2 \mathrm{D}$ ). The behavior of the pile group $2 \times 2$ is close but not the same as with the behavior of pile group $2 \times 1$. In the case of group $3 \times 2$, the lateral pile displacement and lateral soil resistance gave similar values for first and second trailing row. The values of the p-multiplier $\left(f_{m}\right)$ of leading pile are always greater that those obtained for first and 
second trailing pile. Pile spacing of $(\mathrm{s}=2 \mathrm{D}-5 \mathrm{D})$ provides low $f_{m}$ which means that the large effect of group action occurred in this case and the pile within group have no similar behavior compared with behavior of single isolated pile. The values of $f_{m}$ obtained from the pile groups in cohesionless soil are almost larger than the $f_{m}$ magnitudes obtained from pile groups in cohesive soil. The calculated results which were obtained from Eqs. 1 and 2 are more similar in case of trailing row and significantly similar in case of leading row.

Authors' contributions

JM used PLAXIS to simulate and analyzed the case study, both ZC and MR work hard to discuss the results. All authors improve the manuscript as the final form appeared. All authors read and approved the final manuscript.

\section{Author details}

'Department of Civil Engineering, Diyala University, Diyala, Baqubah 32001, Iraq. ${ }^{2}$ Department of Civil and Structural Engineering, Universiti Kebangsaan Malaysia, Bangi Selangor 43600 UKM, Malaysia.

\section{Competing interests}

The authors declare that they have no competing interests.

Ethics approval and consent to participate

Not applicable.

\section{Publisher's Note}

Springer Nature remains neutral with regard to jurisdictional claims in published maps and institutional affiliations.

Received: 22 February 2017 Accepted: 19 December 2017

Published online: 02 January 2018

\section{References}

1. Ashour M, Pilling P, Norris G (2004) Lateral behavior of pile groups in layered soils. J Geotech Geoenviron Eng 130(6):580-592

2. Bowles JE (1988) Foundation analysis and design, 4th edn. McGraw-Hill Companies, New York

3. Brinkgreve RBJ, Broere W (2004) PLAXIS 3D FOUNDATION—version 1. Netherlands

4. Brown DA, Resse LC, O'Neill MW (1987) Cyclic lateral loading of a large-scale pile group. J Geotech Eng ASCE 113(11):1326-1343

5. Brown DA, Morrison C, Reese LC (1988) Laterally load behavior of pile group in sand. J Geotech Eng Div 114(11):1261-1276

6. Brown DA, Shie C-F (1991) Modification of p-y curves to account for group effects on laterally loaded piles. In: Proceedings Geotechnical Engineering Congress, Boulder, Colorado, Jane, 10-12, 1: pp 749-490

7. Chandrasekaran SS, Boominathan A, Dodagoudar GR (2010) Group interaction effects on laterally loaded piles in clay. J Geotech Geoenviron Eng ASCE 136(4):573-582

8. Dunnavant TW, O'Neill MW (1986) Evaluation of design-oriented methods for analysis of vertical pile groups subjected to lateral load. Numerical methods in offshore piling, Inst. Francais du Petrole, Labortoire Central des ponts et Chausses, pp 303-316

9. Duncan JM, Evans LT, Ooi PS (1994) Lateral load analysis of single piles and drilled shafts. J Geotech Eng ASCE 120(6):1018-1033

10. Huang AB, Hseuh C-K, O'Neill MW, Chern S, Chen C (2001) Effects of construction on laterally loaded group piles. J Geotech Geoenviron Eng ASCE 127(5):385-397

11. Ilyas T, Leung CF, Chow YK, Budi SS (2004) Centrifuge model study of laterally loaded pile groups in clay. J Geotech Geoenviron Eng 130(3):274-283

12. Iyer PK, Sam C (1991) 3-D elastic analysis of three-pile caps. J Eng Mech 117(12)

13. Jamaludin A, Hussein AN (1998) The performance of large diameter bored piles used for road project in Malaysia. In: Proceedings of the 3rd International Geotechnical Seminar on Deep Foundation on Bored and Auger Piles, Ghent, Belgium, pp 335-338

14. Johnson K, Lemcke P, Karunasena W, Sivakugan N (2006) Modelling the load_deformation response of deep foundation under oblique load. Environ Model Softw 21:1375-1380

15. Kahyaoglu MR, Imancli G, Ozturk AU, Kayalar AS (2009) Computational 3D finite element analyses of model passive piles, Computational Materials Science, (In Press)

16. Karthigeyan S, Ramakrishna WGST, Rajagopal K (2007) Numerical investigation of the effect of vertical load on the lateral response of piles. J Geotech Geoenviron Eng 133(5):512-521

17. Kotthaus M, Grundhoff T, Jessberger HL (1994) Single piles and pile rows subjected to static and dynamic lateral load. In: Leung CF, Lee FH, Tan TS (eds) Centrifuge 94. Balkema, Rotterdam, pp 497-502

18. Lieng JT (1989) A model for group behavior of laterally loaded piles. Offshore Technology Conference, Houston, pp 377-394 
19. McVay M, Zhang L, Molnit T, Lai P (1998) Centrifuge testing of large laterally loaded pile groups in sands. J Geotech Geoenviron Eng ASCE 124(10):1016-1026

20. Meimon Y, Baguelin F, Jezequel JF (1986) Pile group behaviour under long time lateral monotonic and cyclic loading. In: Proceedings of third international conference on numerical methods in offshore piling. Inst. Francais du Petrole, Nantes, France, pp 285-302

21. Mokwa RL, Duncan JM (2001) Laterally loaded pile group effects and p-y multipliers. ASCE Geotechnical Special Publication, GSP No. 113, Foundations and Ground Improvement, In: Proceedings of the GEO-Odyssey Conference, Blacksburg, pp 728-742

22. Patra NR, Pise PJ (2001) Ultimate lateral resistance of pile groups in sand. J Geotech Geoenviron Eng 127(6):481-487

23. Potts DM, Zdravkovic L (1999) Finite element analysis in geotechnical engineering: theory. Thomas Telford, Heron Quay, London

24. Poulos HG, Davis EH (1980) Pile foundation analysis and design. Wiley, New York

25. Rao SN, Ramakrishna VG, Rao MB (1998) Influence of rigidity on laterally loaded pile groups in marine clay. J Geotech Geoenviron Eng 124(6):842-549

26. Remaud D, Garnier J, Frank R (1998) Laterally loaded piles in dense sand: group effects. In: Proceedings Centrifuge 98, Tokyo, pp 533-538

27. Rollins KM, Peterson KT, Weaver TJ (1998) Lateral load behavior of full-scale pile group in clay. J Geotech Geoenviron Eng 124(6):468-478

28. Rollins KM, Lane JD, Gerber TM (2005) Measured and computed lateral response of a pile group in sand. J Geotech Geoenviron Eng, ASCE. 131(1):103-114

29. Rollins KM, Olsen KG, Jensen DH, Garrett BH, Olsen RJ, Egbert JJ (2006) Pile spacing effects on lateral pile group behavior: analysis. J Geotech Geoenvironmental Eng 132(10):1272-1283

30. Ruesta PF, Townsend FC (1997) Evaluation of laterally loaded pile group at Roosevelt Bridge. J Geotech Geoenviron Eng ASCE 123(12):1153-1161

31. Zhang HH, Small JC (2001) Analysis of capped pile groups subjected to horizontal and vertical loads. Comput Geotech 26:1-21

32. Zhang L, Mc Vay M, Lai P (1999) Numerical analysis of laterally loaded 3×3 to 7×3 pile groups in sands. J Geotech Geoenviron Eng ASCE 125(11):936-946

\section{Submit your manuscript to a SpringerOpen ${ }^{\circ}$ journal and benefit from:}

- Convenient online submission

- Rigorous peer review

- Open access: articles freely available online

- High visibility within the field

- Retaining the copyright to your article

Submit your next manuscript at $\mathbf{s p r i n g e r o p e n . c o m ~}$ 